\title{
Organisational capability for managing biodiversity - a study
}

\begin{abstract}
Ecological problems rooted due to organizational activities have increased significantly, yet the role businesses play in achieving ecological sustainability has not gained much attention. Businesses are not only dependent on biodiversity and its services but have serious impact on ecosystems directly or indirectly. Greater pressure on biodiversity due to business impact will have a rebounding effect which poses risk to business and society at large. The present study explores the possible determinants affecting the adoption of biodiversity conservation strategies by Indian businesses thus identifying the Biodiversity Capability model for Indian businesses. The study has used exploratory approach to understand the trends, practices, and the plethora of biodiversity conservation strategies adopted by companies. The results suggest that biodiversity conservation strategies undertaken by companies were influenced by whether or not the managers of these companies interpreted biodiversity conservation as an opportunity or threat and the propensity of the managers to undertake risk on behalf of their companies.
\end{abstract}

Keywords: Biodiversity conservation, determinants of business and biodiversity linkage; managerial cognitions
Volume 2 Issue I - 2018

\author{
Gautam R, Singh A \\ Environment Engineering and Management, National Institute of \\ Industrial Engineering, India
}

\author{
Correspondence: Richa Gautam, Environment Engineering \\ and Management, National Institute of Industrial Engineering, \\ Mumbai, India, Tel +91 992091473।, \\ Email richagautam07@gmail.com
}

Received: December 08, 2017| Published: January 31, 2018

\section{Introduction}

The stages of economic growth in most countries have been historically dependent on the non-judicious use of natural resources that have a direct productive role, and are clearly identifiable as a market good, by its price. ${ }^{1}$ Under the concept of equitable use of natural resources, the universally accepted premise is that unplanned and uncontrolled growth of business contributes to irreversible degradation to the biological and physical properties of ecosystem. Many studies have focused upon the importance of preservation of nature with the context of preserving National biological capital but few of the studies suggested a role or linkage between biodiversity with business.

India is one of the 17-mega diverse countries of the world. With only $2.5 \%$ of the land area, India already accounts for $7.8 \%$ of the global recorded species. One of the major challenges for India lies in adopting an instrument, which helps to align the objectives of equitable sharing of benefits enumerated in the United Nations Convention on Biological Diversity (CBD, 2012). Attaining a state of equilibrium with biodiversity and building Organisational Capability on the subject has been widely recognized as a core strategy in an increasing number of organizations in developed countries. The present study attempts to identify determinants of the business and biodiversity linkage from a developing country perspective with main emphasis to India. Several biodiversity related acts in India include Biodiversity Act (2002), Wildlife Conservation Act (1972), Forest (Conservation) Act, 1980 etc are prevailing. The Biological Diversity Act (2002) was a result of India's attempt to realise the objectives of CBD for enabling equitable use of Biological Resources. The Act aims at the conservation of biological resources and associated knowledge as well as facilitating access to them in a sustainable manner. The current study will provide a clear understanding of Business and Biodiversity linkages from Sustainability based organisational perspective. Additionally, the proposed research will propose a conceptual model for implementing Biodiversity strategy in an organisation. The implications of the study can be of significant value to organizations that prepare to implement new biodiversity initiatives, or improve upon their existing practices.

Potdar et al. ${ }^{2}$ conducted a qualitative study to capture the biodiversity disclosures of 101 international companies as there were absolutely indistinct disclosures by Indian companies. ${ }^{2}$ This study elaborated how businesses in developed countries addressed the biodiversity issues and whether binding legislation is imposed by the government which drives biodiversity management by businesses. Possible role of factors like managerial interpretation of biodiversity importance, risk propensity of managers and pressure from stakeholders could be responsible for developing biodiversity Capability in a company which can be achieved only when organisations have tangible benefits from biodiversity strategy implementation.

\section{Literature review}

Biodiversity as an additional environment constraint on BusinessAs suggested by Houdet et $\mathrm{al}^{3}{ }^{3}$ firms can no longer consider biodiversity as an external constraint and managing dependencies of Biodiversity needs to be embedded into the organizational value chain (Table 1). Managerial Interpretations on biodiversity managementManagerial interpretations refer to the process by which managers make sense of events and other information. ${ }^{4}$ In the biodiversity context the first dimension relates to managerial interpretations of whether or not actions for reducing environmental impact of corporate operations or for undertaking biodiversity conservation initiatives will have a positive versus a negative impact upon the job performance of manager's and on company operations. The second interpretative dimension relates to environmental responsiveness strategies as contributing to gains through competitive advantage versus having potential of creating losses through costs, risks, liabilities, and investments that do not pay back.

Risk- The risk behaviour of managers refers to decisions, made on behalf of their organisations that involve a degree of risk in the 
expected outcomes (Pablo 1997). ${ }^{5}$ Within the context of biodiversity conservation strategies in developing countries, the possibility of downside outcomes is of greater relevance. This perspective is accounted for in this study by examining the influence of managerial interpretations of biodiversity issues, as threats versus opportunities, on risk behaviour.

Table I Business strategic challenges: dependencies and impacts on biodiversity ${ }^{3}$

\section{Business}

Dependencies on Managing sources, delivery channels and time Biodiversity on Biodiversity

\begin{abstract}
Challenge I: Securing biodiversity services to production/processes/sales
\end{abstract}

Challenge 2:Avoiding and accounting for biodiversity dis- services and associated costs

Business Impacts Challenge 3:Assessing and managing legal responsibilities related to Biodiversity

Challenge 4: Mitigating impacts on Biodiversity through specialised projects

\section{Research gaps}

Absence of business framework for biodiversity: The business capability model for biodiversity has not been conceived in the Indian scenario so far and the studies conducted in this front restrict to environmental strategies only. Such model will not only fill the research gap but also help aid the business for developing biodiversity strategies and deriving long term and short term benefits.

Strategizing biodiversity for Business: Businesses needs to be involved in the National agenda for preserving the natural capital by incorporating a strategy that can prioritize the needs of its people and the environment by not promoting industrial growth which caters only to the requirements of a concentrated few, over the needs of many. The business sector heavily depends on biodiversity for their productivity, although the legal framework is not effective enough to promote biodiversity management. This results in many instances of loss of valuable biodiversity rich forests in lieu of afforestation programmes, which often promote the monoculture plantations of desired species. What's more, companies that fail to comply with the regulations are often denied adequate permissions to operate their business activities and consequently, the cost of doing business increases manifold.

Policy gap: India was the first country to have the Biodiversity Act (2002). In order to implement the Biological Diversity Act 2002, three functional bodies' viz., NBA at the national level, State Biodiversity Boards (SBBs) in different states, and Biodiversity Management Committees (BMCs) at the level of local community (Panchayat) have been established. The Act provides provisions for regulated access to biological resources by bonafide end users for various purposes including scientific research, commercial activities, and sustainable use of non-timber forest produce. The Act was opposed by many groups on various grounds including the lack of clarity on conservation clauses, poor regard to community control, and its endorsement of Intellectua Property Rights (IPRs) as the Act set a framework to grant IPR permissions.

\section{Proposed analytical framework}

A business and biodiversity framework has been developed based on the gaps identified during the exploratory Literature review that elaborates on the determinants affecting business and biodiversity management in business. The Figure 1 below depicts the conceptual framework with determinants of biodiversity management. The framework would help understand various aspects of biodiversity management practices and factors affecting its adoption. The review of Business and biodiversity literature reveals that research conducted so far has been largely oriented towards case studies that seldom provided a model for comprehensive evaluation of Biodiversity management practices in companies. In the Indian context dealing with Biodiversity management of a company for better management of the same is lacking and so is the significance of various factors that influence the implementation of model.

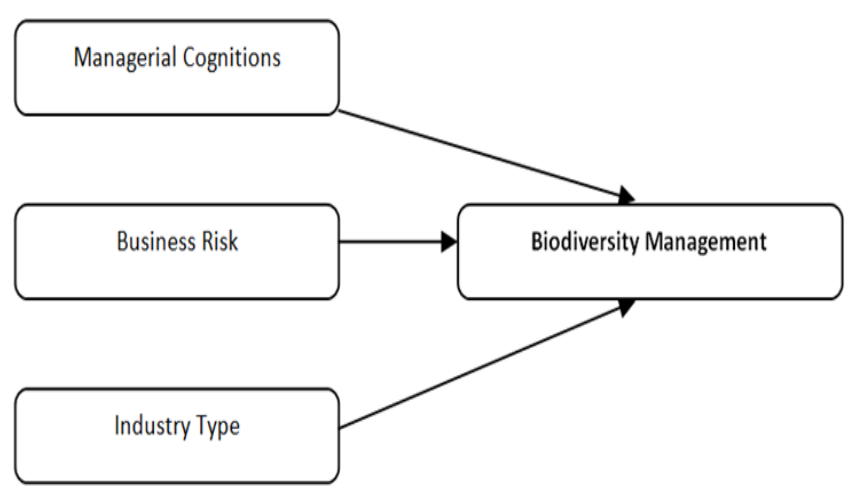

Figure I Conceptual frameworks.

The conceived framework suggests that organisations do have some pre-conditions or antecedent factor as context to establish or support biodiversity management and also, some possible consequent conditions of achieving organisational benefits. The framework suggests that when managers interpret biodiversity as risk or opportunity it would ultimately lead to adherence to defined processes for managing impact to biodiversity and thereby result in framing of targets to achieve the overall objectives of the business continuity. Also, it is believed that the Biodiversity Management strategies were influenced by whether or not the managers of companies interpreted biodiversity as an opportunity or a threat. Therefore, the risk propensity of managers determined their decision to undertake risk on behalf of their companies. The opportunity interpretations of biodiversity management transform into proactive strategies only if the managers exhibit a high risk propensity. The type of business also plays a role in Biodiversity management as the ones that are into extractive business would be more dependent upon biodiversity resources as compared to the services business.

\section{Results and discussion}

At a theoretical level, the exploratory study has helped in understanding the Biodiversity conservation phenomenon from an Indian perspective. This study re-affirms the fact that Biodiversity in organisation is of utmost importance and serves practitioners develop their own Biodiversity strategies and policy formulating more efficiently through the Biodiversity model. The findings reveal that managerial biodiversity interpretation; risk and industry type 
are supposedly the pre-conditions or antecedent factors which have a positive impact on biodiversity conservation strategies. In absence of any binding agreement it can be concluded that even though biodiversity importance has been understood in various business scenarios, implementation lacks an integrated approach in absence of any Biodiversity conservation framework.

The results indicate the limitations of the current conservationist dogma that corporations are not aware of opportunities presented by biodiversity conservation. ${ }^{6}$ Hopefully, over time, the developing countries will gain the financial, technological, and social knowledge that will eventually make them less risky partners in biodiversity conservation ventures. While these companies in advance countries hold the technical expertise and economic motivations for reducing biodiversity erosion, the developing countries hold the biodiversity resources. Immediate solutions are needed for overcoming the risk perceptions of managers in companies and developing the technological and financial capabilities of the developing nations, to avoid the rapid and irreversible loss of the vast wealth and potential benefits that biodiversity can provide from our earth. The next logical step would be to analytically establish the conceptual model as a scope for future research. ${ }^{7-11}$

\section{Acknowledgements}

Thanks to the professors of Center for Science and Environment, NITIE for their guidance and support during the course of research.

\section{Conflict of interest}

Author declares there is no conflict of interest in publishing the article.

\section{References}

1. Gunton T. Natural resources and regional development: an assessment of dependency and comparative advantage paradigms. Economic Geography. 2003;79(1):52-75.

2. Potdar A, Gautam R, Singh A, et al. Business reporting on biodiversity and enhancement of conservation initiatives. International Journal of Biodiversity Science, Ecosystem Services \& Management. 2016;12(3):227-236.

3. Houdet J, Trommetter M, Weber J. Understanding changes in business strategies regarding biodiversity and ecosystem services. Ecological Economics. 2012;73:37-46.

4. Dutton JE, Fahey L, Narayanan UK. Toward understanding strategic issue diagnosis. Strategic Management Journal. 1983;4(4):307-323.

5. Sitkin SB, Pablo AL. Reconceptualizing the determinants and risk behavior. The Academy of Management Review. 1992;17(1):9-38.

6. McNeely JA. Economics and biological diversity: executive summary and guidelines for using incentives. International Union for Conservation of Nature and Natural Resources. Gland, Switzerland; 1988. p. 39.

7. United Nations Convention on Biological Diversity. UNCBD. 1992.

8. National Biodiversity Strategy and Action Plan. 2000-2004.

9. IUCN's Business and Biodiversity. 2007.

10. Indian Forest Act. 1927.

11. Indian Wildlife (Protection) Act. 1972. 